\title{
Chapter
}

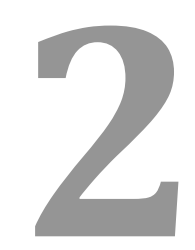

\section{THE PROMISING ROLE FOR ADIPOSE-DERIVED MESENCHYMAL STEM CELLS IN TISSUE REGENERATION}

Anirudh Arun, W.P. Andrew Lee, Gerald Brandacher, and Angelo Alberto Leto Barone*

Johns Hopkins University, Department of Plastic and Reconstructive Surgery, Baltimore, MD 


\section{Contents}

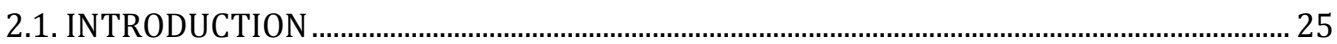

2.2. FOREIGN BODY IMMUNE RESPONSES IN TISSUE ENGINEERING.................................... 25

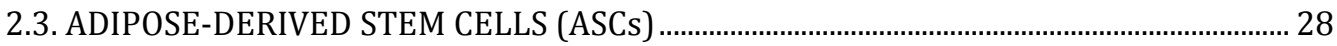

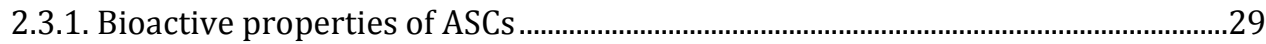

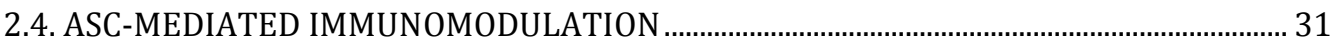

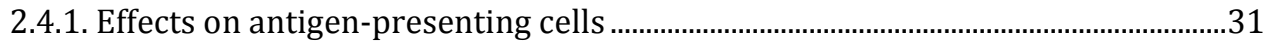

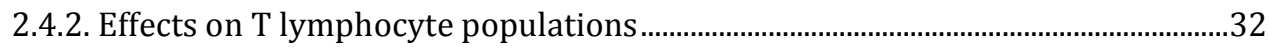

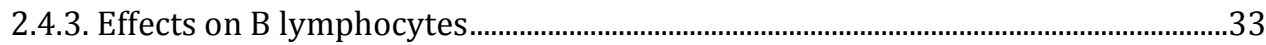

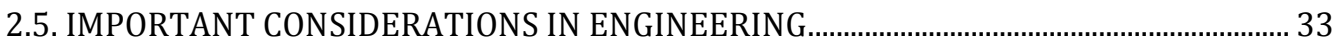

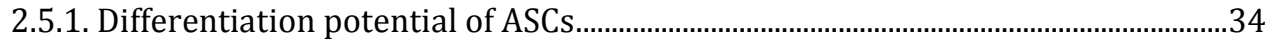

2.6. CURRENT THERAPEUTIC APPLICATIONS OF ASCs .............................................................. 35

2.6.1. Immunomodulation in transplantation and immune-mediated disease ............35

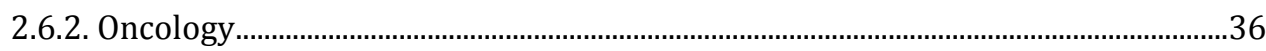

2.7. INTEGRATION OF ASCs WITH SCAFFOLDS AND ARTIFICIAL CONSTRUCTS................. 37

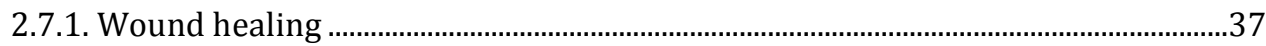

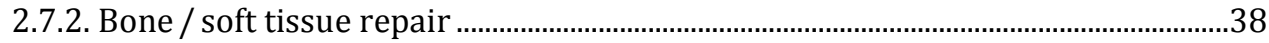

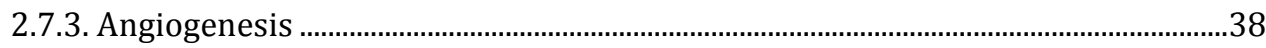

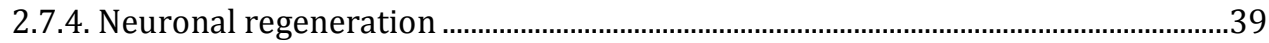

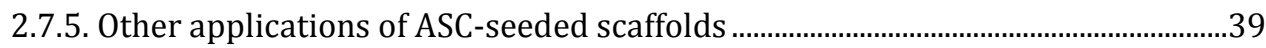

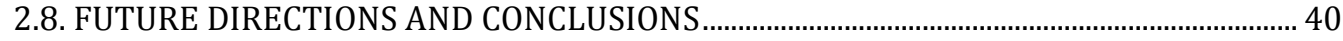

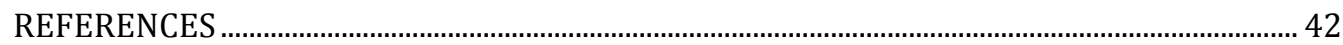




\subsection{INTRODUCTION}

Biomaterials and engineered tissue constructs face a significant risk of failure due to the immune response to such foreign bodies. While synthetic materials can be precisely engineered to maximize the desired therapeutic effects, further interventions are needed to mitigate this host response. A new area of research has focused on the immunomodulatory properties of adipose-derived mesenchymal stem cells (ASCs), which have been demonstrated in numerous in vitro and in vivo studies to significantly modulate immune responses and immune cell activity in a variety of contexts.

Since stem cell-seeded constructs and scaffolds have already been developed, it naturally follows whether ASCs can be incorporated into future iterations of engineered tissues to reduce the negative effects of a host immune response against the therapeutic intervention. This chapter will focus on evidence for the promising role of ASCs in facilitating the successful therapeutic implantation of engineered tissues by means of immunomodulation.

\subsection{FOREIGN BODY IMMUNE RESPONSES IN TISSUE ENGINEERING}

Surgical insertion of an engineered scaffold for tissue engineering will yield a two-fold reaction: one mediating acute wound healing, and another mediating the foreign body response to the artificial substrate. The former process has been well studied and follows a highly predictable course. Acute wound healing is mediated primarily by immune cells (such as neutrophils and macrophages), associated chemokines / cytokines, platelets, fibroblasts, among other mediators intrinsic to the damaged tissue. The clotting cascade, mediated by platelets and fibrin clots, initiates the healing process, and leads to secretion of platelet-derived growth factor (PDGF) and transforming growth factor- $\beta$ (TGF- $\beta$ ). These factors, as well as mast cell degranulation, facilitates the chemotactic influx of inflammatory cells such as neutrophils. TGF- $\beta$ also serves to guide matrix deposition in conjunction with other signaling mediators. Epithelialization and subsequent fibrosis of the wound leads to final closure [1].

The foreign body response to the biomaterial has significant implications on the functionality and success of that device/tissue and this is a significant challenge for engineers, clinicians, and researchers today. Mitigating the complex immune response to a foreign body serves as a critical point of therapeutic intervention to increase the chance of success in tissue engineering applications. Initial interactions between blood components (particularly plasma proteins and complement mediators) [2] and the biomaterial directly 
induce subsequent acute and chronic inflammatory processes, resulting in infiltration of the material and the surrounding tissue by neutrophils, lymphocytes, and monocytes. Macrophages, unable to phagocytose the biomaterial, undergo fusion to form the giant cells that characterize the foreign body response. A complex array of signaling molecules and cellular mediators orchestrates this process [3]. An overview of the foreign body response is depicted in Figure 1.

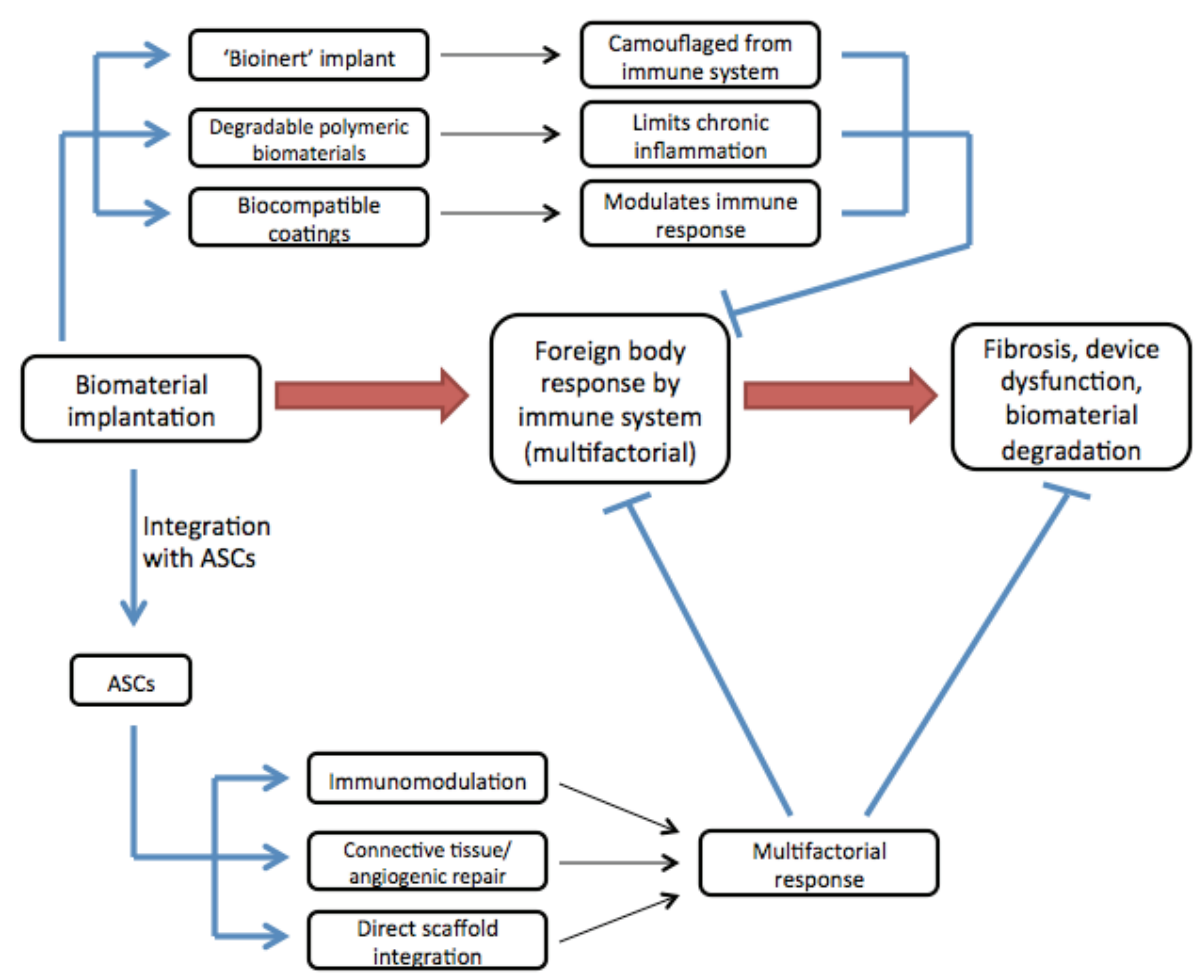

Figure 1. Overview of the foreign body response to biomaterial implantation and current strategies to minimize its effects

The fibrotic response to foreign bodies has significant downstream effects on the functionality of a biomaterial, particularly if the material is bioactive with regards to delivery of drugs or signaling molecules [4]. Fibrosis and inflammatory responses have also been shown to loosen implanted calcium phosphate-containing organic matrices used in bone regeneration [5]. The pre-existing inflammatory milieu in myocardial infarction, in addition to response to the scaffolds used in cardiac patches for assisted tissue regeneration can decrease the survival of cells within the engineered patch [6]. Thus, it becomes evident that control and modulation of the immune response is critical for the success of a therapeutic intervention involving engineered 
tissues and biomaterials, and that biomaterial failure due to pathological fibrosis and immune activation is present in a wide array of therapeutic applications.

Initial studies into this immune response and technological limitations urged biomaterial engineers to either account for inevitable fibrosis or minimize antigenicity of the material components [7]. However, achievement of truly 'bioinert' substances remains challenging, and, thus, biomaterials must be designed in such a way so as to adaptively regulate the immune response, rather than hide from it. In order to achieve this, further characterization of the foreign body immune response in terms of intercellular interactions, phenotypic diversity of the cellular mediators, signaling mediators, and qualities of the scaffold material itself can result in proactive interventions to mitigate the negative effects of pathological fibrosis [8-10].

One approach involved the exploration of degradable polymeric biomaterials. Use of more permanent biomaterials can result in a chronic inflammatory process, leading to increased risk of therapeutic failure. The benefit of degradable constructs is that the host immune response will be inherently self-limited. However, it is necessary to ensure that degradation products of these temporary scaffold structures are non-toxic [11]. Specific modulation of macrophage response to biomaterials has also been suggested by utilizing materials with uniform, spherical, and interconnected pores, modulation of nano-scale biomaterial topography, local interleukin-4 (IL-4) administration, and administration of phosphatidylserine-presenting liposomes (to mimic anti-inflammatory characteristics of apoptosis [12]. Biomaterials can also be modified to modulate macrophage adhesion by grafting specific peptide sequences to the material surface [13].

Other techniques have included coating with biocompatible materials, such as natural polymers and synthetic hydrogels. However, these coatings may themselves be immunogenic and prone to degradation over time, in addition to concerns regarding coating adherence to the biomaterial and safety of synthetic coatings [14]. Local reservoirs of steroids or non-steroidal anti-inflammatory drugs (NSAIDs) can also serve to artificially modulate the immune response to the foreign body. Enhancement of vascularization around the biomaterial may prove necessary in certain applications, and can be achieved by addition of vascular endothelial growth factor (VEGF) and limiting use of corticosteroid immunomodulatory agents [14].

While multiple approaches currently exist to limit pathological fibrosis of biomaterials used in tissue engineering, no consistent or comprehensive solution exists to effectively modulate the entire immune response. The best solution would be an adjunct to the existing biomaterial that can modulate the immune system with a response that is itself susceptible to feedback. It should also be readily incorporable into existing scaffolds in a wide variety of therapeutic contexts, and enhance pro-tolerogenic immunologic effects 
towards biomaterials in a diverse, multifactorial manner. For this reason, adipose-derived stem cells, which have been demonstrated to have potent immunomodulatory effects, and can readily seed scaffolds used in tissue engineering, can serve a powerful role in enhancing the survival of engineered tissues [15].

\subsection{ADIPOSE-DERIVED STEM CELLS (ASCS)}

Adipose-derived stem cells (ASCs) are a type of mesenchymal stem cell (MSC), which are defined as a cell population that displays adherence to plastic, a specific array of surface antigen expression, and differentiation potential into osteoblast, adipocyte, and chondrocyte lineages [16]. MSCs are isolated from a wide range of tissues, such as bone marrow, placenta, thymus, Wharton's jelly, umbilical cord blood, and adipose tissue, among a number of other tissue sources [17]. Molecular characterization of ASCs from uncultured stromal vascular fraction includes a surface marker expression panel of CD 45-CD235a-CD31-CD34+CD13+CD73+CD90+CD105+. Since ASCs share molecular characteristics with bone marrow-derived MSCs, ASCs can be uniquely characterized from the latter by expression of CD36 and lack of CD106 expression [18]. ASCs are also capable of differentiating into neuronal [19] and myocyte lineages [20,21].

One of the most appealing qualities of ASCs is the relative ease of isolating such cells from body tissues. Protocols have been developed to allow for collection of 250,000-375,000 ASCs from a single milliliter of human lipoaspirate following 4-6 days of culture in $10 \%$ fetal bovine serum. Since lipoaspirate is readily collected during liposuction, tremendous numbers of ASCs can be relatively easily isolated from patients for use in therapeutic interventions $[15,22]$. Trypsin-mediated tissue digestion for ASC isolation may also provide an inexpensive method to harvest this cell population following lipoaspiration [23]. Successful culture of ASCs in xeno-free media without serum has also been achieved, further supporting consistent isolation and maintenance of ASCs in economically efficient in vitro conditions [24].

ASCs have been shown to have therapeutic potential in a wide range of clinical contexts. Addition of ASCs to skin wounds was shown to result in improved healing dynamics, particularly with enhanced angiogenesis/capillary formation in the wound site, increased epithelialization, and better cosmetic results due to decreased scarring. Wound healing enhancement was attributed to both ASC differentiation and release of paracrine molecules [25]. ASCs were also shown to facilitate resolution of chronic, nonhealing wounds [26].

Other current therapeutic applications of ASCs include acceleration of peripheral nerve regeneration following injury [27], regeneration of bone and cartilage, and to facilitate survival of fat grafts in breast augmentation and facial lipoatrophy [28]. ASCs have also served therapeutic roles in 
rehabilitation of cardiac function following myocardial infarction / ischemia as well ischemic injury due to peripheral vascular disease. Preliminary evidence for ASC-derived-insulin-secreting cells in the treatment of Type 1 Diabetes has also demonstrated promising results. The role of ASC in fistula repair has been explored, although currently remains inconclusive [29].

Ultimately, the features of ASCs that allow for such widespread therapeutic benefits in a variety of clinical contexts make it a promising candidate for the demands of enhancing success in the clinical use of engineered tissues.

\subsubsection{Bioactive properties of ASCs}

ASCs have been shown to have significant immunomodulatory properties, in addition to secretion of growth factors. In promoting immunological tolerance and facilitating growth of an engineered tissue construct, ASCs can serve a significant role in the success of therapeutic interventions involving tissue engineering. Not only can stem cells be used to provide cell types needed for tissue regeneration, but the pleiotropic paracrine-mediated effects of ASCs can also facilitate a rich, pro-healing environment.

What exactly constitutes the secretome of ASCs that make it such a potently bioactive cell population? Signaling mediators include growth factors and immunomodulatory agents such as TGF- $\beta$, hepatocyte growth factor (HGF), VEGF, indoleamine-2,3 dioxygenase (IDO), interleukin-10 (IL-10), prostaglandin E2 (PGE2), nitric oxide (NO), heme oxygenase 1 (HO-1), and human leukocyte antigen (HLA-G) among numerous other mediators [30,31]. Other MSC subpopulations are known to secrete IL-6, IL-8, and IL-12, as well as interferon-gamma (IFN- $\gamma$ ), macrophage colony stimulating factor (M-CSF), and hepatocyte growth factor (HGF) [17,32]. While the secretome of the cell population has been closely studied, one cannot also ignore the many secondary effects of ASC-mediated signaling. By modulating secretory patterns of other cells, local ASC administration can have systemic modulations of various extracellular signals, mediators, and structural proteins [33]. However, the ASC secretome has been shown to have intrinsic immunomodulatory effects without the need for ASCs simultaneously present, as evidenced by an experiment demonstrating variation in the level of various cytokines following infusion of a mouse with the supernatant of an ASC culture [34].

The secretome can be characterized by analyzing various functional consequences of ASC paracrine signaling (Figure 2). Angiogenesis mediated by ASCs is largely due to secretion of TGF- $\beta$, VEGF, and basic fibroblast growth factor (bFGF) [31]. Secretion of these pro-vascularizing signals is thought to be induced by a localized state of hypoxia $[35,36]$. Furthermore, ASCs may display characteristics of pericytes and directly secrete various regulatory proteins that control and organize networks of endothelial cells into functional vasculature [37]. In the context of wound healing, ASCs were shown to potentiate this process through the secretion of some of the various growth 
factors and extracellular matrix (ECM) components discussed above, such as collagen I, fibronectin, fibroblast growth factor 2 , VEGF, and TGF- $\beta$, among other signaling mediators $[31,38]$.

Both of these qualities are critically important for the functionalization of an engineered tissue implant. Enhanced vascularization facilitates oxygenation of the otherwise ischemic tissue, in addition to delivery of various metabolic substrates needed for implanted cells to function properly in their therapeutic environment. Activation of wound healing processes leads to secretion and deposition of ECM components, leading to the integration of the implanted biomaterial into surrounding tissue, enhancing its therapeutic success. Although the immune response poses a significant barrier, ASCs are sufficiently capable of reducing this adverse effect.

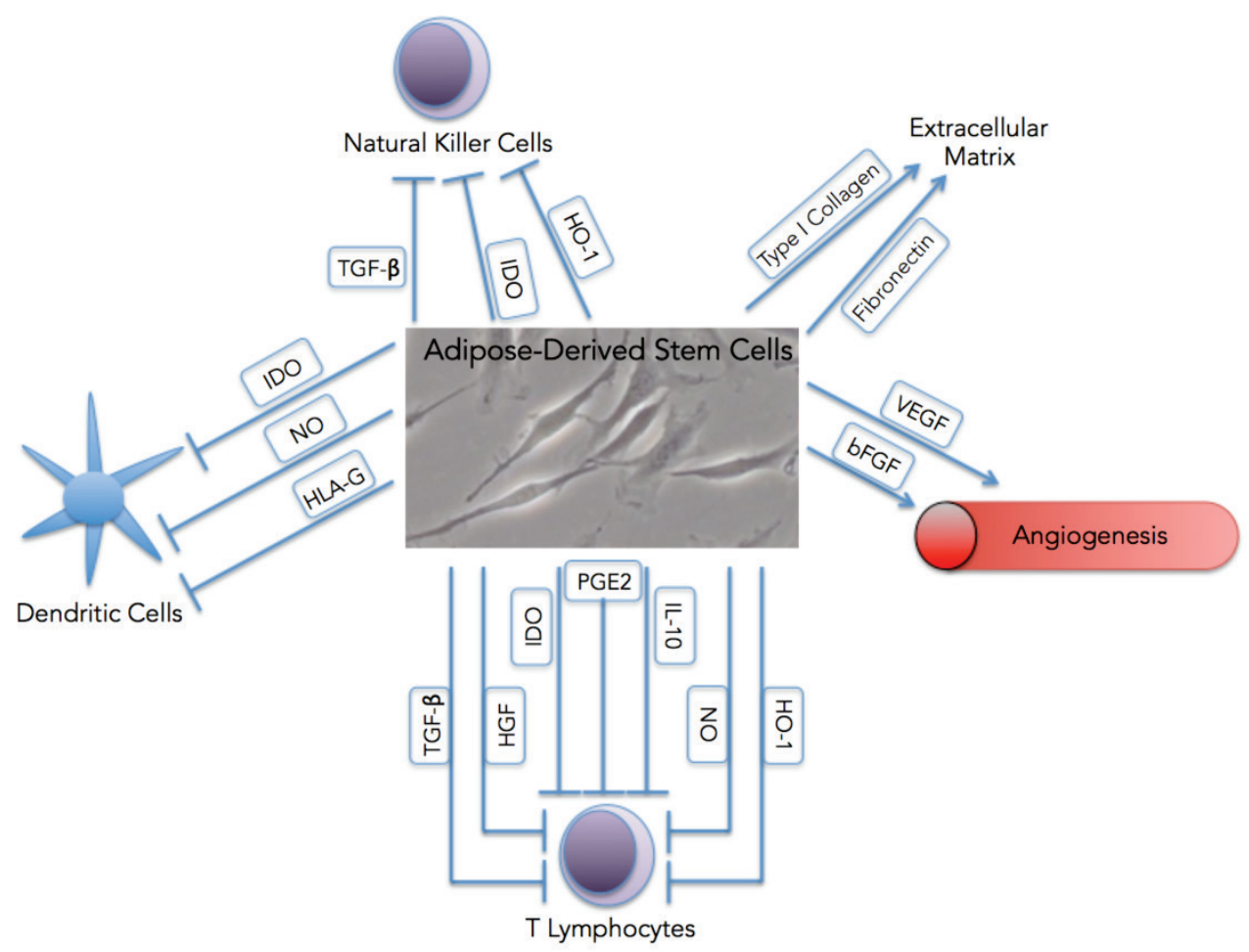

Figure 2. Immunomodulatory and angiogenic secretome of ASCs (image from American Research Products) [30,31,39-41] 


\subsection{ASC-MEDIATED IMMUNOMODULATION}

The immunomodulatory capacities of MSCs are widespread, affecting various cellular members of the immune system such as T cells, B cells, dendritic cells (DCs), and natural killer cells [42]. However, such capacities differ among the different sources of MSCs, and various studies have looked into identifying the most potent stem cell population for immunomodulatory effects. ASCs have been demonstrated to be more potent at immunomodulation as compared to MSCs isolated from bone marrow (BMSCs) with respect to suppression of peripheral blood mononuclear cell (PBMC) proliferation, inhibition of monocyte differentiation into DCs, and show a higher level of cytokine secretion [43]. Another study compared ASCs and BMSCs with regards to effects on lymphocytes and found the two cell populations to have similar immunosuppressive capacities, dependent highly on the number of cells while also 'highly variable' between different samples of isolated ASCs [44]. Another group demonstrated that MSCs isolated from placenta can show greater immunomodulatory effects than either ASCs or BMSCs [45].

Interestingly, the immunosuppressive properties of ASCs may continue after subsequent differentiation, as proposed by a study examining such properties following TGF- $\beta 3$-induced chondrogenesis of ASCs [46]. Additionally, ASCs genetically modified to overexpress IL-4 were shown to have a stronger anti-inflammatory response in the context of experimental autoimmune demyelination [47]. Ultimately, the potent immunomodulatory properties of ASCs may play a role in a diverse array of therapeutic functions, from mediating tolerance in HLA-mismatched cell-based therapies and potentially restoring immunological balance in autoimmunity.

\subsubsection{Effects on antigen-presenting cells}

Since the immune system consists of a diverse set of players, it is important to understand how MSCs / ASCs are able to modulate the activity and behavior of each cellular component [17]. DCs and macrophages are efficient antigenpresenting cells (APCs), serving a critical initiating role for inflammation by the immune system [42]. Since APCs serve to deliver antigens from scaffolds and other components in engineered tissues to induce the downstream inflammatory response, effective suppression of APC activity can serve a significant role in maintaining the integrity of the engineered construct. Factors secreted by ASCs have been shown to inhibit differentiation of monocytes and DCs. Furthermore, ASCs are able to affect DC endocytosis, hinder migration of DCs to lymph nodes, induce regulatory phenotypes in both macrophages and DCs, and modulate downstream T cell activation [48-52]. Thus, potent modulation of APC activity by MSCs / ASCs can be utilized effectively to increase success in the context of engineered tissues.

Downstream of APC endocytosis of the antigen is its presentation to effector arms of the immune system, including CD4+ $\mathrm{T}$ cells that activate other arms of 
the immune system. Interestingly, ASCs have potent effects on T lymphocytes as well. ASCs can affect helper $\mathrm{T}$ cell differentiation by changing the intracellular milieu of transcription factors and cytokine secretion profile $[42,53]$. It was previously noted that Th1 differentiation could be affected downstream of DC immunomodulation [50]. Specific suppression of the Th17 [54] and Th2 [55] subsets by ASCs has also been observed. In cross-species interaction of human ASCs with murine T lymphocytes in vitro, the mechanism of suppression of $\mathrm{T}$ cell proliferation was demonstrated to involve cyclooxygenase-2 (COX-2) [56]. Another group demonstrated a significant role for PGE2 in modulating T lymphocyte transcription factors and cytokines to underlie the immunosuppressive effects. Interestingly, exosomes of ASCs were shown to be sufficient in inducing suppressive effects on $\mathrm{T}$ cell activation, differentiation, proliferation, and IFN- $\gamma$ secretion [57]. With regards to cytotoxic T lymphocytes, MSCs could suppress development of but not actual cell lysis by these cells [58].

\subsubsection{Effects on $T$ lymphocyte populations}

Direct inhibition of T cell activity by ASCs in a model of rat orthotopic liver transplantation was shown to reduce acute rejection [59]. Similar effects were shown in the ASC-mediated immunosuppression of human $\mathrm{T}$ cells from patients with rheumatoid arthritis [60]. The ASC-mediated suppressive effects on $\mathrm{T}$ cells, although with great therapeutic benefit, may however come with dangerous consequences. ASCs in breast cancers may modulate T cells in such a way so as to induce a tolerogenic environment, thereby protecting tumor cells from immune attack [61].

In addition to direct immunosuppression of effector $\mathrm{T}$ cell populations, MSCs / ASCs are capable of inducing the proliferation and maintenance of both $\mathrm{CD}^{+}$and $\mathrm{CD}^{+}$regulatory $\mathrm{T}$ cell (Treg) populations $[60,62]$. The elevated presence of Tregs around an engineered implant can enhance immune tolerance of the artificial material. It has been demonstrated that the Tregs induced by ASCs are functional and capable of suppressing proliferation of effector immune cells [63]. Low oxygen conditions were shown to facilitate Treg induction by ASCs [64], which can be of particular utility in engineered implants, which are not immediately vascularized and thus experience locally hypoxic conditions. Supplementation of ASCs to the post-transplant regimen in a rat model of vascularized composite allotransplantation led to increased numbers of Tregs in circulation, which was implicated in the enhanced post-transplant tolerogenesis in these rats [65]. 


\subsubsection{Effects on B lymphocytes}

Immunomodulation by ASCs does not end with APCs and T lymphocyte subsets, but may also include regulation on the level of B lymphocytes and natural killer (NK) cells. BMSCs have been shown to suppress B lymphocyte proliferation via the programmed death ligands (PD-L1 and PD-L2) [66]. Other effects on B cells by MSCs include suppression of terminal differentiation [67], in vitro inhibition of antibody production [68], and downregulation of factors necessary for chemotaxis [69]. ASCs, in particular, can induce the development of a regulatory B cell population, further controlling B cell activity [70]. MSCs have been known to suppress activity of NK cells with regards to IFN- $\gamma$ secretion and proliferation $[51,71,72]$. ASCs, specifically, are capable of such suppression [73] and are themselves poorly susceptible to lysis by NK cells [74].

\subsection{IMPORTANT CONSIDERATIONS IN ENGINEERING}

The immunomodulatory properties of ASCs are in turn modulated by a diverse list of variables. Local presence of IFN- $\gamma$ from T and NK cells is necessary for MSC-mediated immunomodulation, as this resulted in secretion of IDO by the MSCs to suppress the activity of other immune mediators [75,76]. IFN- $\gamma$ stimulation of MSCs was also associated with MHC-II expression, which weighs heavily in MSC antigen presentation and subsequent allogenicity [77]. It is important to note that ASC-mediated suppression of T cell proliferation is strongly dependent on its passage, with early passage ASCs actually stimulating proliferation, and later passage cells suppressing it [78]. Thus, the immunomodulatory characteristics of the ASCs in an engineered construct will depend on the inflammatory microenvironment around the implant.

Application of ASCs/MSCs in engineered tissues requires culturing and integration of cells in vitro within constructs. Subsequent proliferation of MSCs may have effects on their immunomodulatory capacities due to degradation of telomeres. Extension of telomeres through enhanced expression of telomerase was shown to retain immunosuppressive capabilities in the immortalized cell lines [79]. Beneficial to its proposed application in controlling inflammatory responses against engineered tissues, ASCs also demonstrate increased potential for immunosuppression in an inflammatory environment [80]. The age of the donor appears to be inversely proportional to the immunosuppressive capacity of the isolated ASCs as well [81].

Particularly important to engineering processes, the method by which ASCs are cultured can also weigh significantly on their immunomodulatory capacity [82]. This finding was corroborated by a later study, which also demonstrated the ability to isolate and expand ASCs in xeno-free and serum-free media, although this negatively impacts its immunosuppressive properties. Hypoxia 
also markedly enhances the functions of ASCs, which is useful in poorly vascularized tissue initially surrounding artificial implants. These functional changes include increased proliferation, anti-apoptotic and angiogenic factor secretion, and altered adhesion dynamics to ECM proteins $[25,83]$.

\subsubsection{Differentiation potential of ASCs}

In addition to serving an immunoprotective role towards the engineered tissue, ASCs are also capable of differentiating into various soft and connective tissues that facilitate integration of that specific tissue into the body (Figure 3). ASCs are multipotent, being able to undergo adipogenic, osteogenic, myogenic, and chondrogenic differentiation, (differentiation is limited to mesodermic lineages) [84]. Interestingly, according to some, ASC spheroids showed similar chondrogenic potential as BMSCs in a monolayer, but were less effective than the latter in cartilaginous differentiation in high-density 3D culture formed from spheroidal aggregates of cells [85]. Human ASCs have also demonstrated the ability to develop a smooth muscle-like morphology [86]. ASCs can also be induced into a neuronal lineage, serving another exciting role for this cell population in the realm of tissue engineering [87]. Other applications include direct differentiation into corneal epithelial-like cells [88], dentine pulp tissue [89], cell types similar to pancreatic $\beta$ cells with insulin-secreting capabilities [90], and cardiomyocyte-like cells for post-myocardial infarction repair $[89,91,92]$.

As mentioned above, the pro-angiogenic properties of ASCs provide an exciting platform in the realm of tissue engineering. Since the surgical integration of an engineered tissue implant naturally results in loss of perfusion to that area, a proper return of blood flow through direct endothelial differentiation and VEGF secretion in that area is needed to supply nutrients and oxygen to regenerative cells [93]. ASCs have thus demonstrated potent roles for angiogenic repair in ischemic tissues, such as in myocardial infarction [94]. ASCs have been shown to not only directly differentiate into endothelial cells and incorporate into existing vascular structures [95], but may also have a role in supporting that population. Abluminal localization and subsequent development of pericyte-, smooth muscle-, and mesenchymal-like properties in ASCs allows ASCs to directly interact with endothelial cells to maintain the functional and structural aspects of vasculature [96]. These interactions have already been demonstrated to potentiate angiogenesis around implants, raising the possibility for its clinical use in tissue engineering [97]. 


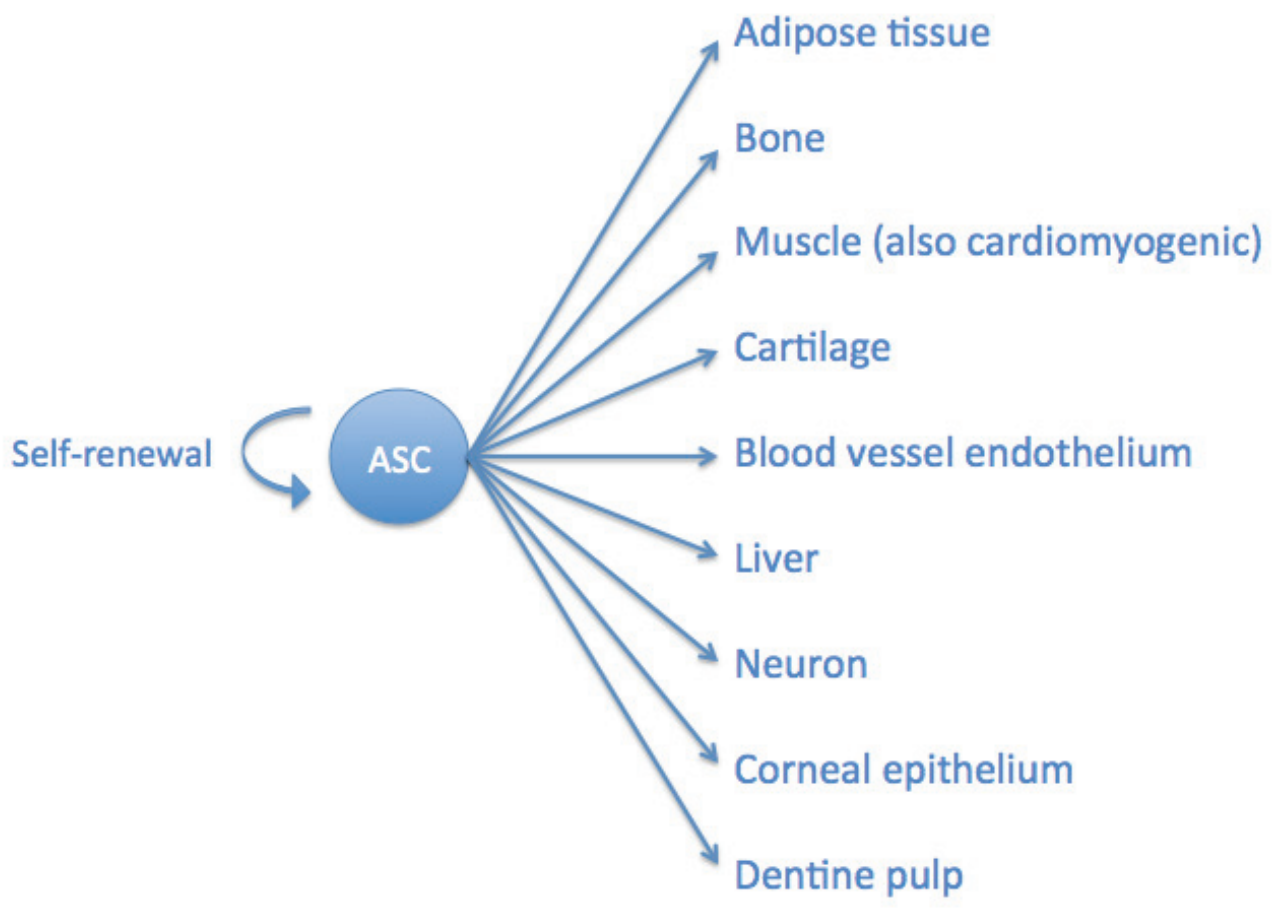

Figure 3. Demonstrated differentiation potential of ASCs

\subsection{CURRENT THERAPEUTIC APPLICATIONS OF ASCS}

The bioactive properties of ASCs have been extensively studied in a wide range of clinical contexts, from effects on tumors to post-transplantation immunosuppression and autoimmune conditions. This extensive array of evidence lends credence to the fascinating potential of these cells in treating and mitigating disease. This, coupled with the relative ease by which they can be isolated, creates an exciting future for ASCs.

\subsubsection{Immunomodulation in transplantation and immune-mediated disease}

Tolerance to engineered tissues can be likened to that which is required following allogenic transplant. Current post-transplant immunosuppressive regimens contain chemical suppressors of immune mediator proliferation. New research suggests that supplementation of this regimen with immunomodulatory ASCs can enhance the development of tolerance and reduce the onset of rejection [102]. This combination therapy was demonstrated to have significant results in tolerogenesis in an orthotopic hind-limb vascularized composite allotransplantation model in rats [103]. 
These successful results have also been demonstrated in large animal models, with enhanced prolongation of heterotopic hind-limb transplantation in swine [104]. Several potential issues must be noted in the use of ASCs / MSCs in post-transplant regimens. These include maintenance of the ASC populations in vivo due to natural clearance, specifications regarding dosage and method of delivery, and the potential for drugs in the post-transplant regimen to themselves negatively modulate the immunomodulatory capacity of ASCs [105]. The potential for success in using ASCs in transplant has been demonstrated in a humanized mouse model of skin grafts [106] and even in a patient who underwent kidney transplant [107]. Evidence also exists for the capacity of ASCs to mitigate the severity of graft-versus-host-disease (GVHD) following bone marrow transplant [108].

Immunomodulation by ASCs has proved useful in the context of autoimmune and immune-mediated diseases. Systemic treatment with ASCs has been showed to decrease Th1 response and increase Treg levels (with associated elevation in IL-10 levels) to alleviate the severity of colitis in a murine model of drug-induced colitis $[109,110]$. Early evidence also points to the utility of MSCs as a therapeutic adjunct in the treatment of multiple sclerosis [111,112]. Through suppression of Th1 and Th17 subsets in combination with upregulation of Tregs, ASCs were demonstrated to improve outcomes in murine experimental autoimmune hearing loss [113]. This immunosuppression of $\mathrm{T}$ lymphocytes was also demonstrated to reduce the severity of symptoms in rheumatoid arthritis [60]. ASCs were also shown to decrease the incidence of necrosis following autologous fat grafting [114]. Through the upregulation of VEGF and IL-10, intracerebral implantation of ASCs demonstrated significantly improved functional outcomes in a mouse model of Alzheimer's disease [115].

The vast potential of ASCs is readily apparent. This cell population is readily available and plentiful in lipoaspirates, isolatable by various protocols, and has a rich array of bioactive properties ranging from immunosuppression to localized enhancement of growth and repair. As implanted engineered tissues face hefty challenges from the host immune response and demand localized wound repair for proper integration into the body, the mechanisms by which ASCs have been demonstrated to modulate local environments in vitro and in vivo can be harnessed through integration into scaffolds and artificial constructs. This is another promising area of study, and is discussed in the following section.

\subsubsection{Oncology}

Stem cell therapy appears to have a mixed picture when it comes to induction or reduction of cancerous tumors. As was previously stated, the combination of growth factor secretion and immunosuppression by localized presence of ASCs can protect and induce the growth of breast cancer cells [61]. Breast cancer 
cells co-cultured with ASCs were shown to have increased markers for malignancy and may lead to worse outcomes [98]. ASCs increased motility and metastasis of cancer cells and may stabilize tumor vasculature in breast cancers as well [99]. Interestingly, stromal tissue isolated from adipose tissue was shown to lead to increased cell death in pancreatic cancers [100]. ASCs also demonstrate the capacity to hone on tumor cells, and this has been used therapeutically to assist in drug delivery to these sites [101].

\subsection{INTEGRATION OF ASCs WITH SCAFFOLDS AND ARTIFICIAL CONSTRUCTS}

To realize the full potential of ASCs enhancing the successes of engineered tissues, it is first necessary to understand how ASCs can be integrated into scaffolds currently used in these applications. Evidence has existed for over a decade regarding the seeding of scaffolds with ASCs. A 2005 publication examining techniques to facilitate osteochondral engineering determined that ASCs could be successfully integrated into chitosan scaffolds without undue toxicity on those cells [116]. The adhesive properties of the scaffold specifically to encourage ASC attachment and proliferation can be enhanced by the application of specific peptide sequences to its surface [117]. ASCs were also shown to have potential in tissue engineering particularly in vascular generation through seeding of tubular scaffolds [118] and adipogenesis following seeding of gelatin sponges [119]. ASCs were also proposed for the seeding of calcium phosphate scaffolds to facilitate surgical repair in spinal fusion [120].

Considerable research has been conducted to determine specific characteristics of the scaffold that facilitate the use of ASCs in various clinical contexts. Not only does the material of the scaffold weigh heavily on ASC seeding and subsequent proliferation and differentiation, but also the pore size and shape, which has significant effects on vascularization of the biomaterial. Understanding how various scaffold-based technologies have proven useful in laboratory and clinical settings can yield useful information into how ASCs can be integrated into existing tissue engineering applications across the body.

\subsubsection{Wound healing}

One area where ASCs have proven useful is in the context of wound healing. As previously mentioned, the hypoxic conditions within the wound coupled with the angiogenic properties and differentiation capabilities of ASCs make them potent candidates to accelerate the wound healing process. However, effective use of these cells requires their integration into a matrix that can be easily applied within the wound, which may be irregularly shaped. Acellular scaffolds may facilitate these functions of ASCs, and this has been hypothesized to be an effective solution to enhance wound healing [121]. Cell sheets of ASCs have 
been demonstrated to enhance the degree of wound healing in a mouse model [122.123]. One study found that ASCs integrated into an ECM patch were necessary for their survival and subsequent enhancement of skin wound healing in mice [124]. Hydrogels have been shown to maintain ASC viability within the wound, thereby prolonging their healing capacities for a longer period of time [125]. Decay in ASC healing properties may be mitigated by the use of low level laser therapy, which can act to stimulate these cells [126]. In terms of biomaterials, chitosan and PLCP-P123 (nonwoven nanofibrous material with structural similarity to ECM) scaffolds have been shown to be effective in the wound healing process mediated by ASCs [127-129].

\subsubsection{Bone / soft tissue repair}

Effective scaffold-based ASC therapy can also prove useful in the treatment of defects in bone by optimizing the osteogenic potential of these cells. As in skin wound healing, the architecture and composition of the scaffold plays a critical role in this process. Scaffolds that bear resemblance to bone (calcium phosphate-based scaffold with polycaprolactone and hydroxyapatite components), particularly those that have been co-cultured with osteoblasts, show success in facilitating ASC differentiation into bone within the architecture of the scaffold [130]. As seen previously in skin wound healing, use of low-level laser therapy can enhance bone regeneration as well [131]. In addition to mimicking scaffolds with natural bone, the density of the scaffold structure also weighs on the differentiation potential of ASCs [132]. A recent study demonstrated that a stacked scaffold structure can also enhance the osteogenic potential of ASCs [133].

\subsubsection{Angiogenesis}

Scaffold material (either naturally derived or synthetically generated) has also been shown to weigh on ASC angiogenic potential [134]. Seeding of ASCs into commercial dermal substitutes can also promote angiogenesis $[135,136]$. It is interesting to note that the method by which ASCs are integrated into the scaffold (injection $v s$. onlay seeding) can play a role in the extent of subsequent vascularization of the graft due to differential effects on migration of cells through that scaffold [137]. Additionally, seeding of ASC spheroids into a porous polyurethane scaffold proved more effective at facilitating growth of a higher density of vessels than seeding with individual ASCs [138]. However, the angiogenic potential of ASCs need not require direct contact by those cells. Encapsulation of ASC spheroids with a polytetrafluoroethylene filtration membrane, which allows soluble mediators to diffuse into the local environment, demonstrated increased vascularization in that area [139]. 


\subsubsection{Neuronal regeneration}

Scaffold-integrated ASCs can also facilitate neuronal regeneration. The use of decellularized adipose tissue as the ECM scaffold grafted into a mouse model of cavernous nerve damage to simulate post-prostatectomy injury, demonstrated neural regrowth and return of penile erection [140]. Seeding of ASCs into porous gelatin and chitosan scaffolds grafted into mouse model of traumatic brain injury also revealed enhanced repair, attributed to induction of ASC differentiation into neuron-like morphologies [141,142]. Targeted axonal repair following transection and Wallerian degeneration is also enhanced with the use of nerve guidance conduits seeded with ASCs [143].

\subsubsection{Other applications of ASC-seeded scaffolds}

This platform has been utilized in a variety of other clinical contexts as well (Figure 4). Submucosa-seeded ASCs enhance erectile function following damage to tunica albuginea and application of the graft over the injury [144]. Virally modified ASCs integrated into a 3D PLGA/alginate scaffold demonstrated a method to promote the development of cartilage [145]. Scaffolds of decellularized cadaveric tendon seeded with ASCs also facilitated regeneration of tendon tissue through direct induction of tenocyte differentiation $[146,147]$. Pelvic floor reconstruction, specifically in the context of fascia regeneration, was also enhanced with ASC-seeded implants [148].

What are some of the factors of the scaffold that may regulate ASC activity? As stated before, the actual composition of the scaffold can weigh heavily on this point. Development of scaffolds of composite material mixed with decellularized adipose tissue demonstrated greater ASC viability and subsequent differentiation into adipogenic lineages [149]. These properties were also encouraged by seeding ASCs in layers of calcium alginate hydrogels [150]. Surface modification of a chitosan-based scaffold allowed for a push towards ASC differentiation into cardiac muscle [151]. Use of polyhydroxybutyrate / poly(hydroxybutyrate-co-hydroxyhexanoate) scaffolds enhanced cartilage development from seeded ASCs [152].

Several treatment conditions can encourage ASC seeding and integration into scaffolds. One demonstrated technique to improve adhesion of ASCs to non-woven poly(L-lactic acid) scaffolds is oxygen plasma treatment prior to seeding [153]. Culture conditions, specifically the media / serum, also can have an effect on initial density of ASC seeding of scaffolds [154]. These studies reveal that the exact material of the scaffold, any modifications to the biomaterial, and architecture will have to be tailored carefully to optimize the desired effects of the seeded ASCs. Therefore in future applications of ASCs to enhance the effectiveness of engineered tissues, one must consider how the scaffold can affect the activity and differentiation potential of ASCs, in addition to effects on vasculogenesis, which is largely affected by pore architecture. 


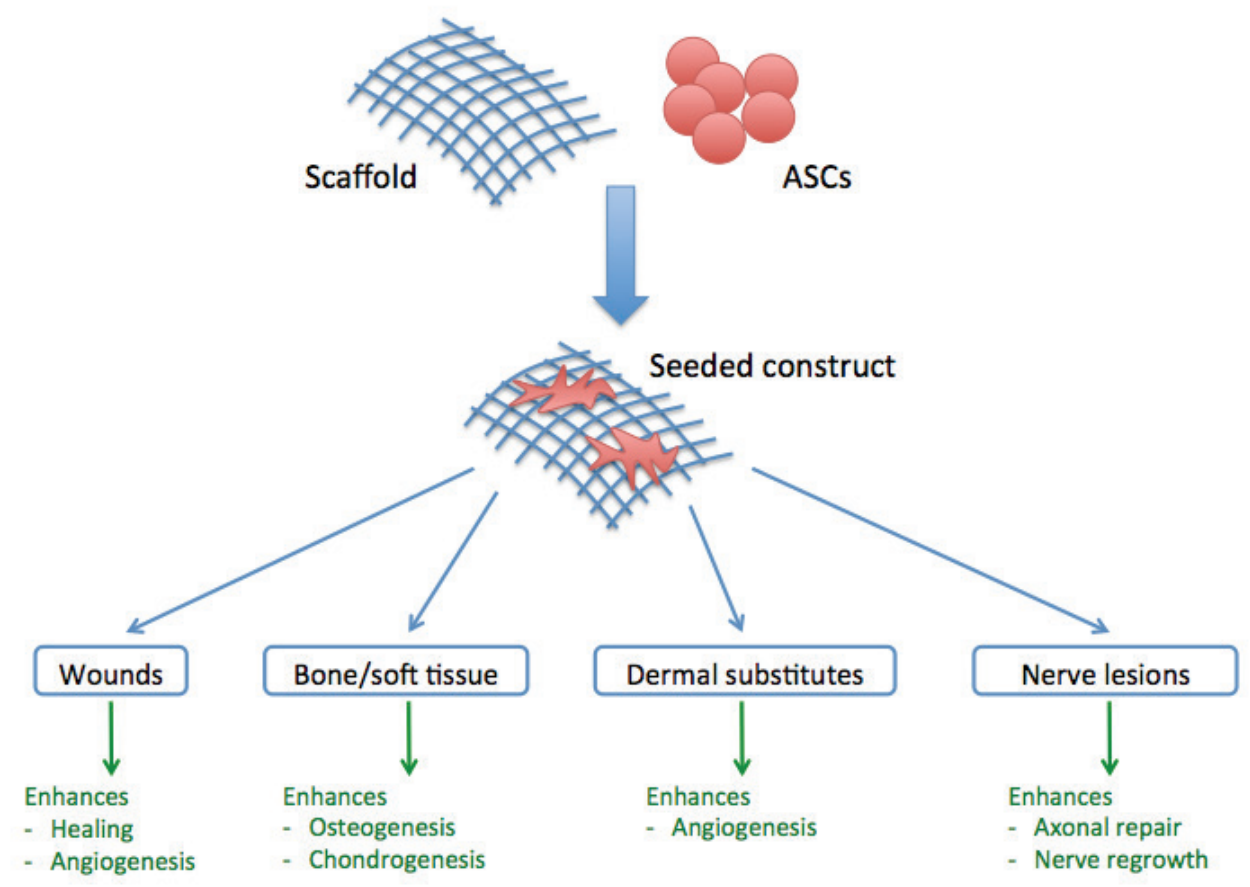

Figure 4. Overview of demonstrated uses and subsequent benefits of ASC-seeded scaffolds in clinical contexts

\subsection{FUTURE DIRECTIONS AND CONCLUSIONS}

All of this established evidence points to a promising future for ASCs in tissue engineering. This is a highly versatile and readily available cell population that has repeatedly demonstrated characteristics favoring its use in this clinical context. Its multipotent properties, ability to secrete a variety of growth-inducing and immunomodulatory mediators (hence the term immunomodulatory secretome), and ability to integrate into existing scaffold materials point to its increased use in new biomaterials and artificial tissues.

However, much work remains before ASCs can become a feasible treatment modality. Current regulations restrict the breadth of ASC-based therapies such that cells must remain within the operating room with the patient. To date, if cells are brought outside the operating room to undergo culturing or engineering in a laboratory, they may not be replaced into a patient. Patient safety is of paramount concern, and in vivo animal studies as well as preliminary human safety trials must be conducted to open the doors to further testing. With strong evidence available regarding its benefits, ASC-based therapies must address these necessary safety concerns to open the 
doors to further, but well-regulated, clinical studies.All benefits and challenges of ASCs are listed in Figure 5.

\section{Positive}

- Found in multiple tissue sources

- Easily isolatable in large numbers from lipoaspiration

- Established culture protocols

- Bioactive properties (immunomodulation, angiogenesis...)

- Multipotent differentiation capacity

- Incorporable into 3D synthetic scaffolds

\section{Negative}

- Restrictive regulations for clinical use

- Few in vivo human studies

- Need to fully understand how to control ASC proliferation and differentiation

Figure 5. Benefits and challenges of using ASCs in clinical applications

In conclusion, the many challenges currently experienced by bioengineers, clinicians, and translational researchers in the effective in vivo application of biomaterials may be mitigated or solved by the effective addition to ASCs. However, further work remains to be done to fully characterize and describe their clinical potential and safety to achieve full clinical use. Although ASCs are largely limited to laboratory use and study at this point, as discoveries emerge and as regulations will change, these cells will offer an exciting new chapter in the field of regenerative medicine. 


\section{REFERENCES}

1. $\quad$ R.F. Diegelmann, M.C. Evans. Front. Biosci. 9 (2004) 283-289.

2. B. Nilsson, K.N. Ekdahl, T.E. Mollnes, J.D. Lambris. Mol. Immunol. 44 (2007) 82-94.

3. J.M. Anderson, A. Rodriguez, D.T. Chang. Semin. Immunol. 20 (2008) 86-100.

4. $\quad$ K.S. Jones. Semin. Immunol. 20 (2008) 130-136.

5. $\quad$ F. Velard, J. Braux, J. Amedee, P. Laquerriere. Acta Biomater. 9 (2013) 4956-4963.

6. D.O. Freytes, L. Santambrogio, G. Vunjak-Novakovic. Cells Tissues Organs 195 (2012) 171-182.

7. J.M. Morehead, G.R. Holt. Otolaryngol. Clin. North Am. 27 (1994) 195-201.

8. P.M. Kou, J.E. Babensee. J. Biomed. Mater. Res. A 96 (2011) 239-260.

9. Y. Garcia, A. Breen, K. Burugapalli, P. Dockery, A. Pandit. Biomaterials 28 (2007) 175-186.

10. R.J. Love, K.S. Jones. Crit. Rev. Biomed. Eng. 37 (2009) 259-281.

11. $\quad$ E.E. Falco, M. Patel, J.P. Fisher. Pharm. Res. 25 (2008) 2348-2356.

12. N. Mokarram, R.V. Bellamkonda. Ann. Biomed. Eng. 42 (2014) 338-351.

13. W.J. Kao. Biomaterials 20 (1999) 2213-2221.

14. J.M. Morais, F. Papadimitrakopoulos, D.J. Burgess. AAPS J. 12 (2010) 188-196.

15. J.M. Gimble, B.A. Bunnell, T. Frazier, B. Rowan, F. Shah, C. Thomas-Porch, $\mathrm{X}$. Wu. Organogenesis 9 (2013) 3-10.

16. M. Dominici, K. Le Blanc, I. Mueller, I. Slaper-Cortenbach, F. Marini, D. Krause, R. Deans, A. Keating, DJ. Prockop, E. Horwitz. Cytotherapy 8 (2006) 315-317.

17. A. Rahimzadeh, F.S. Tabatabaei Mirakabad, A. Movassaghpour, K. Shamsasenjan, S. Kariminekoo, M. Talebi, A. Shekari, V. Zeighamian, M. Gandomkar Ghalhar, A. Akbarzadeh. Artif. Cells Nanomed. Biotechnol. (2014) 1-12.

18. P. Bourin, B.A. Bunnell, L. Casteilla, M. Dominici, A.J. Katz, K.L. March, H. Redl, J.P. Rubin, K. Yoshimura, J.M. Gimble. Cytotherapy 15 (2013) 641-648.

19. H. Ning, G. Lin, T.F. Lue, C.S. Lin. Differentiation 74 (2006) 510-518.

20. Y.S. Choi, G.J. Dusting, S. Stubbs, S. Arunothayaraj, X.L. Han, P. Collas, W.A. Morrison, R.J. Dilley. J. Cell. Mol. Med. 14 (2010) 878-889.

21. P.A. Zuk, M. Zhu, H. Mizuno, J. Huang, J.W. Futrell, A.J. Katz, P. Benhaim, H.P. Lorenz, M.H. Hedrick. Tissue Eng. 7 (2001) 211-228.

22. M. Zhu, S. Heydarkhan-Hagvall, M. Hedrick, P. Benhaim, P. Zuk. J. Vis. Exp. (2013) e50585.

23. C.F. Markarian, G.Z. Frey, M.D. Silveira, E.M. Chem, A.R. Milani, P.B. Ely, A.P. Horn, N.B. Nardi, M. Camassola. Biotechnol. Lett. 36 (2014) 693-702.

24. B. Lindroos, S. Boucher, L. Chase, H. Kuokkanen, H. Huhtala, R. Haataja, M. Vemuri, R. Suuronen, S. Miettinen. Cytotherapy 11 (2009) 958-972.

25. W.U. Hassan, U. Greiser, W. Wang. Wound Repair Regen. 22 (2014) 313-325.

26. M. Cherubino, J.P. Rubin, N. Miljkovic, A. Kelmendi-Doko, K.G. Marra. Ann. Plast. Surg. 66 (2011) 210-215.

27. S.D. Zack-Williams, P.E. Butler, D.M. Kalaskar. World J. Stem Cells 7 (2015) 51-64.

28. D.A. Banyard, A.A. Salibian, A.D. Widgerow, G.R. Evans. J. Cell. Mol. Med. 19 (2015) 21-30.

29. M.H. Lim, W.K. Ong, S. Sugii. Expert Rev. Mol. Med. 16 (2014) e8. 
30. E. Soleymaninejadian, K. Pramanik, E. Samadian. Am. J. Reprod. Immunol. 67 (2012) 1-8.

31. S.K. Kapur, A.J. Katz. Biochimie 95 (2013) 2222-2228.

32. M. Abumaree, M. Al Jumah, R.A. Pace, B. Kalionis. Stem Cell Rev. 8 (2012) 375-392.

33. Y.R. Kuo, C.C. Chen, S. Goto, Y.T. Huang, C.C. Tsai, M.Y. Yang. Plast. Reconstr. Surg. 134 (2014) 1213-1223.

34. S.M. Lee, S.C. Lee, S.J. Kim. J. Surg. Res. 188 (2014) 280-289.

35. H. Suga, J.P. Glotzbach, M. Sorkin, M.T. Longaker, G.C. Gurtner. Ann. Plast. Surg. 72 (2014) 234-241.

36. K. Kondo, S. Shintani, R. Shibata, H. Murakami, R. Murakami, M. Imaizumi, Y. Kitagawa, T. Murohara. Arterioscler. Thromb. Vasc. Biol. 29 (2009) 61-66.

37. S. Rohringer, P. Hofbauer, K.H. Schneider, A.-M. Husa, G. Feichtinger, A. Peterbauer-Scherb, H. Redl, W. Holnthoner. Angiogenesis 17 (2014) 921-933.

38. B.S. Park, K.A. Jang, J.H. Sung, J.S. Park, Y.H. Kwon, K.J. Kim, W.S. Kim. Dermatol. Surg. 34 (2008) 1323-1326.

39. H. Yagi, A. Soto-Gutierrez, B. Parekkadan, Y. Kitagawa, R.G. Tompkins, N. Kobayashi, M.L. Yarmush. Cell Transplant 19 (2010) 667-679.

40. S.H. Ranganath, O. Levy, M.S. Inamdar, J.M. Karp. Cell. Stem Cell 10 (2012) 244-258.

41. G. Ferrari, B.D. Cook, V. Terushkin, G. Pintucci, P. Mignatti. J. Cell. Physiol. 219 (2009) 449-458.

42. V. Machado Cde, P.D. Telles, I.L. Nascimento. Rev. Bras. Hematol. Hemoter. 35 (2013) 62-67.

43. S.M. Melief., J.J. Zwaginga, W.E. Fibbe, H. Roelofs. Stem Cells Transl. Med. 2 (2013) 455-463.

44. B. Puissant, C. Barreau, P. Bourin, C. Clavel, J. Corre, C. Bousquet, C. Taureau, B. Cousin, M. Abbal, P. Laharrague, L. Penicaud, L. Casteilla, A. Blancher. Br. J. Haematol. 129 (2005) 118-129.

45. J.M. Lee, J. Jung, H.J. Lee, K.J. Cho, S.G. Hwang, G.J. Kim. Int. Immunopharmacol. 13 (2012) 219-224.

46. A. Technau, K. Froelich, R. Hagen, N. Kleinsasser. Cytotherapy 13 (2011) 310-317.

47. N.L. Payne, A. Dantanarayana, G. Sun, L. Moussa, S. Caine, C. McDonald, D. Herszfeld, C.C.A. Bernard, C. Siatskas. Cell. Adh. Migr. 6 (2012) 179-189.

48. G.M. Spaggiari, H. Abdelrazik, F. Becchetti, L. Moretta. Blood 113 (2009) 6576-6583.

49. W. Zhang, W. Ge, C. Li, S. You, L. Liao, Q. Han, W. Deng, R.C. Zhao. Stem Cells Dev. 13 (2004) 263-271.

50. W. Peng, T. Gao, Z.L. Yang, S. Zhang, M.L. Ren, Z.G. Wang. Cell. Immunol. 278 (2012) 152-157.

51. S. Aggarwal, M.F. Pittenger. Blood 105 (2005) 1815-1822.

52. P. Anderson, L. Souza-Moreira, M. Morell, M. Caro, F. O'Valle, E. Gonzalez-Rey, M. Delgado. Gut 62 (2013) 1131-1141.

53. A. Mohammadzadeh, A.A. Pourfathollah, S. Shahrokhi, S.M. Hashemi, S.L. Moradi, M. Soleimani. Int. Immunopharmacol. 20 (2014) 316-321.

54. K. Lai, K. Zeng, F. Zeng, J. Wei, G. Tan. Acta Biochim. Biophys. Sin. (Shanghai) 43 (2011) 805-812. 
55. $\quad$ K.S. Cho, H.J. Roh. Curr. Stem Cell Res. Ther. 5 (2010) 111-115.

56. J.H. Kim, Y.T. Lee, J.M. Hong, Y.I. Hwang. Anat. Cell. Biol. 46 (2013) 262-271.

57. R. Blazquez, F.M. Sanchez-Margallo, O. de la Rosa, W. Dalemans, V. Alvarez, R. Tarazona, J.G. Casado. Front. Immunol. 5 (2014) 556.

58. I. Rasmusson, O. Ringden, B. Sundberg, K. Le Blanc. Transplantation 76 (2003) 1208-1213.

59. C.D. Wan, R. Cheng, H.B. Wang, T. Liu. Hepatobiliary Pancreat. Dis. Int. 7 (2008) 29-33.

60. E. Gonzalez-Rey, M.A. Gonzalez, N. Varela, F. O’Valle, P. Hernandez-Cortes, L. Rico, D. Büscher, M. Delgado. Ann. Rheum. Dis. 69 (2010) 241-248.

61. M. Razmkhah, M. Jaberipour, N. Erfani, M. Habibagahi, A.R. Talei, A. Ghaderi. Cell. Immunol. 266 (2011) 116-122.

62. K. Le Blanc, O. Ringden. J. Intern. Med. 262 (2007) 509-525.

63. A.U. Engela, M.J. Hoogduijn, K. Boer, N.H.R. Litjens, M.G.H. Betjes, W. Weimar, C.C. Baan. Clin. Exp. Immunol. 173 (2013) 343-354.

64. T.P. Frazier, J.B. McLachlan, J.M. Gimble, H.A. Tucker, B.G. Rowan. Stem Cells Dev. 23 (2014) 968-977.

65. H.Y. Cheng, N. Ghetu, W.C. Huang, Y.L. Wang, C.G. Wallace, C.J. Wen, H.C. Chen, L.Y. Shih, C.F. Lin, S.M. Hwang, S.K. Liao, F.C. Wei. Cytotherapy 16 (2014) 369380.

66. A. Augello, R. Tasso, S.M. Negrini, A. Amateis, F. Indiveri, R. Cancedda, G. Pennesi. Eur. J. Immunol. 35 (2005) 1482-1490.

67. S. Asari, S. Itakura, K. Ferreri, C.P. Liu, Y. Kuroda, F. Kandeel, Y. Mullen. Exp. Hematol. 37 (2009) 604-615.

68. P. Comoli, F. Ginevri, R. Maccario, M.A. Avanzini, M. Marconi, A. Groff, A. Cometa, M. Cioni, L. Porretti, W. Barberi, F. Frassoni, F. Locatelli. Nephrol. Dial. Transplant. 23 (2008) 1196-1202.

69. A. Corcione, F. Benvenuto, E. Ferretti, D. Giunti, V. Cappiello, F. Cazzanti, M. Risso, F. Gualandi, G.L. Mancardi, V. Pistoia, A. Uccelli. Blood 107 (2006) 367-372.

70. M. Franquesa, F.K. Mensah, R.T. Huizinga, T. Strini, L. Boon, E. Lombardo, O. DelaRosa, J.D. Laman, J.M. Grinyó, W. Weimar, M.G.H. Betjes, C.C. Baan, M.J. Hoogduijn. Stem Cells 33 (2015) 880-891.

71. G.M. Spaggiari, A. Capobianco, H. Abdelrazik, F. Becchetti, M.C. Mingari, L. Moretta. Blood 111 (2008) 1327-1333.

72. J.M. Ryan, F.P. Barry, J.M. Murphy, B.P. Mahon. J. Inflamm. (Lond.) 2 (2005) 8.

73. A. Ribeiro, P. Laranjeira, S. Mendes, I. Velada, C. Leite, P. Andrade, F. Santos, A. Henriques, M. Grãos, C.M.P. Cardoso, A. Martinho, M.L. Pais, C. Lobato da Silva, J. Cabral, H. Trindade, A. Paiva. Stem Cell. Res. Ther. 4 (2013) 125.

74. O. DelaRosa, B. Sánchez-Correa, S. Morgado, C. Ramírez, B. del Río, R. Menta, E. Lombardo, R. Tarazona, J.G. Casado. Stem Cells Dev. 21 (2012) 1333-1343.

75. M. Krampera, L. Cosmi, R. Angeli, A. Pasini, F. Liotta, A. Andreini, V. Santarlasci, B. Mazzinghi, G. Pizzolo, F. Vinante, P. Romagnani, E. Maggi, S. Romagnani, F. Annunziato. Stem Cells 24 (2006) 386-398.

76. B. Kronsteiner, S. Wolbank, A. Peterbauer, C. Hackl, H. Redl, G.M. van, C. Gabriel. Stem Cells Dev. 20 (2011) 2115-2126.

77. J.L. Chan, K.C. Tang, A.P. Patel, L.M. Bonilla, N. Pierobon, N.M. Ponzio, P. Rameshwar. Blood 107 (2006) 4817-4824. 
78. K. McIntosh, S. Zvonic, S. Garrett, J.B. Mitchell, Z.E. Floyd, L. Hammill, A. Kloster, Y. Di Halvorsen, J.P. Ting, R.W. Storms, B. Goh, G. Kilroy, X.Y. Wu, J. M. Gimble. Stem Cells 24 (2006) 1246-1253.

79. S. Wolbank, G. Stadler, A, Peterbauer, A. Gillich, M. Karbiener, B. Streubel, M. Wieser, H. Katinger, M. van Griensven, H. Redl, C. Gabriel, J. Grillari, R. Grillari-Voglauer. Tissue Eng. Part A 15 (2009) 1843-1854.

80. M.J. Crop, C.C. Baan, S.S. Korevaar, J.N.M. IJzermans, M. Pescatori, A.P. Stubbs, W.F. J van IJcken, M.H. Dahlke, E. Eggenhofer, W. Weimar, M.J. Hoogduijn. Clin. Exp. Immunol. 162 (2010) 474-486.

81. B.A. Scruggs, J.A. Semon, X. Zhang, S. Zhang, A.C. Bowles, A.C. Pandey, K.M. Imhof, A.V. Kalueff, J.M. Gimble, B.A. Bunnell. Stem Cells Transl. Med. 2 (2013) 797-807.

82. C. Menard, L. Pacelli, G. Bassi, J. Dulong, F. Bifari, I. Bezier, J. Zanoncello, M. Ricciardi, M. Latour, P. Bourin, H. Schrezenmeier, L. Sensebé, K. Tarte, M. Krampera. Stem Cells Dev. 22 (2013) 1789-1801.

83. X. Wang, C. Liu, S. Li, Y. Xu, P. Chen, Y. Liu, Q. Ding, W. Wahafu, B. Hong, M. Yang. PLoS One 10 (2015) e0118951.

84. P.A. Zuk, M. Zhu, P. Ashjian, D.A. De Ugarte, J.I. Huang, H. Mizuno, Z.C. Alfonso, J.K. Fraser, P. Benhaim, M.H. Hedrick. Mol. Biol. Cell. 13 (2002) 4279-4295.

85. A. Winter, S. Breit, D. Parsch, K. Benz, E. Steck, H. Hauner, R.M. Weber, V. Ewerbeck, W. Richter. Arthritis Rheum. 48 (2003) 418-429.

86. J.M. Gimble, A.J. Katz, B.A. Bunnell. Circ. Res. 100 (2007) 1249-1260.

87. K.M. Safford, K.C. Hicok, S.D. Safford, Y.D. Halvorsen, W.O. Wilkison, J.M. Gimble, H.E. Rice. Biochem. Biophys. Res. Commun. 294 (2002) 371-379.

88. T. Nieto-Miguel, S. Galindo, R. Reinoso, A. Corell, M. Martino, J.A. Pérez-Simón, M. Calonge. Curr. Eye Res. 38 (2013) 933-944.

89. R.H. Kim, S. Mehrazarin, M.K. Kang. Dent. Clin. North Am. 56 (2012) 651-675.

90. A.V. Vanikar, S.D. Dave, U.G. Thakkar, H.L. Trivedi. Stem Cells Int. (2010) 582382.

91. M. Peran, E. Lopez-Ruiz, L. Gonzalez-Herrera, M. Bustamante, A. Valenzuela, J.A. Marchal. Cytotherapy 15 (2013) 1541-1548.

92. K. Song, Z. Wang, W. Li, C. Zhang, M. Lim, T. Liu. Appl. Biochem. Biotechnol. 170 (2013) 459-470.

93. F. De Francesco, V. Tirino, V. Desiderio, G. Ferraro, F. D'Andrea, M. Giuliano, G. Libondi, G. Pirozzi, A. De Rosa, G. Papaccio. PLoS One 4 (2009) e6537.

94. R. Madonna, Y.J. Geng, R. De Caterina. Arterioscler. Thromb. Vasc. Biol. 29 (2009) 1723-1729.

95. V. Planat-Benard, J.S. Silvestre, B. Cousin, M. André, M. Nibbelink, R. Tamarat, M. Clergue, C. Manneville, C. Saillan-Barreau, M. Duriez, A. Tedgui, B. Levy, L. Pénicaud, L. Casteilla. Circulation 109 (2004) 656-663.

96. D.O. Traktuev, S. Merfeld-Clauss, J. Li, M. Kolonin, W. Arap, R. Pasqualini, B.H. Johnstone, K.L. March. Circ. Res. 102 (2008) 77-85.

97. D.O. Traktuev, D.N. Prater, S. Merfeld-Clauss, A.R. Sanjeevaiah, M.R. Saadatzadeh, M. Murphy, B.H. Johnstone, D.A. Ingram, K.L. March. Circ. Res. 104 (2009) 1410-1420.

98. J.W. Kuhbier, V. Bucan, K. Reimers, S. Strauss, A. Lazaridis, S. Jahn, C. Radtke, P.M. Vogt. Plast. Reconstr. Surg. 134 (2014) 414-423. 
99. F.L. Muehlberg, Y.H. Song, A. Krohn, S.P. Pinilla, L.H. Droll, X. Leng, M. Seidensticker, J. Ricke, A.M. Altman, E. Devarajan, W. Liu, R.B. Arlinghaus, E.U. Alt. Carcinogenesis 30 (2009) 589-597.

100. B. Cousin, E. Ravet, S. Poglio, F. De Toni, M. Bertuzzi, H. Lulka, I. Touil, M. André, J.L. Grolleau, J.M. Péron, J.P. Chavoin, P. Bourin, L. Pénicaud, L. Casteilla, L. Buscail, P. Cordelier. PLoS One 4 (2009) e6278.

101. L. Kucerova, V. Altanerova, M. Matuskova, S. Tyciakova, C. Altaner. Cancer Res. 67 (2007) 6304-6313.

102. S.S. Tholpady, R.C. Ogle, A.J. Katz. Curr. Opin. Organ Transplant 14 (2009) 51-55.

103. Y.R. Kuo, C.C. Chen, S. Goto, I.-T. Lee, C.-W. Huang, C.-C. Tsai, C.-T. Wang, C.-L. Chen. Plast. Reconstr. Surg. 128 (2011) 661e-672e.

104. Y.R. Kuo, S. Goto, H.S. Shih, F.S. Wang, C.C. Lin, C.T. Wang, E.Y. Huang, C.L. Chen, F.C. Wei, X.X. Zheng, W.P. Lee. Transplantation 87 (2009) 1769-1777.

105. J.A. Plock, J.T. Schnider, M.G. Solari, X.X. Zheng, V.S. Gorantla. Front. Immunol. 4 (2013) 175.

106. M. Roemeling-van Rhijn, M. Khairoun, S.S. Korevaar, E. Lievers, D.G. Leuning, J.N.M. IJzermans, M.G.H. Betjes, P.G. Genever, C. van Kooten, H.J.W. de Fijter, T.J. Rabelink, C.C. Baan, W. Weimar, H. Roelofs, M.J. Hoogduijn, M.E. Reinders. J. Stem Cell Res. Ther. Suppl 6 (2013) 20780.

107. A.V. Vanikar, H.L. Trivedi, S.C. Gopal, A. Kumar, S.D. Dave. Ren. Fail. 36 (2014) 457-460.

108. B. Fang, Y.P. Song, L.M. Liao, Q. Han, R.C. Zhao. Bone Marrow Transplant 38 (2006) 389-390.

109. M.A. Gonzalez, E. Gonzalez-Rey, L. Rico, D. Buscher, M. Delgado. Gastroenterology 136 (2009) 978-989.

110. E. Gonzalez-Rey, P. Anderson, M.A. Gonzalez, L. Rico, D. Buscher, M. Delgado. Gut 58 (2009) 929-939.

111. B. Yamout, R. Hourani, H. Salti, W. Barada, T. El-Hajj, A. Al-Kutoubi, A. Herlopian, E.K. Baz, R. Mahfouz, R. Khalil-Hamdan, N.M. Kreidieh, M. El-Sabban, A. Bazarbachi. J Neuroimmunol 227 (2010) 185-189.

112. M. Mohyeddin Bonab, S. Yazdanbakhsh, J. Lotfi, K. Alimoghaddom, F. Talebian, F. Hooshmand, A. Ghavamzadeh, B. Nikbin. Iran J. Immunol. 4 (2007) 50-57.

113. Y. Zhou, J. Yuan, B. Zhou, A.J. Lee, A.J. Lee, M. Ghawji Jr, T.J. Yoo. Immunology 133 (2011) 133-140.

114. M.S. Piccinno, E. Veronesi, P. Loschi, M. Pignatti, A. Murgia, G. Grisendi, I. Castelli, Da. Bernabei, O. Candini, P. Conte, P. Paolucci, E. M. Horwitz, G. De Santis, L. Iughetti, M. Dominici. Apoptosis 18 (2013) 1274-1289.

115. S. Kim, K.A. Chang, J. Kim, H.-G. Park, J.C. Ra, H.-S. Kim, Y.-H. Suh. PLoS One 7 (2012) e45757.

116. B.M. PP, A.J. Pedro, A. Peterbauer, C. Gabriel, H. Redl, R.L. Reis. J. Mater. Sci. Mater. Med. 16 (2005) 1077-1085.

117. L.Y. Santiago, R.W. Nowak, J. Peter Rubin, K.G. Marra. Biomaterials 27 (2006) 2962-2969.

118. P. DiMuzio, L. Fischer, S. Mcllhenny, C. DiMatteo, N. Golesorhki, D. Grabo, N. Tarola, A. Mericli, I. Shapiro, T. Tulenko. Vascular 14 (2006) 338-342.

119. L. Hong, I.A Peptan, A. Colpan, J.L. Daw. Cells Tissues Organs 183 (2006) 133-140. 
120. M.N. Helder, M. Knippenberg, J. Klein-Nulend, P.I. Wuisman, Tissue Eng. 13 (2007) 1799-1808.

121. C. Nie, D. Yang, S.F. Morris. Med. Hypotheses 72 (2009) 679-682.

122. M.M. McLaughlin, K.G. Marra, Organogenesis 9 (2013) 79-81.

123. Y.C. Lin, T. Grahovac, S.J. Oh, M. Ieraci, J.P. Rubin, K.G. Marra. Acta Biomater. 9 (2013) 5243-5250.

124. M.T. Lam, A. Nauta, N.P. Meyer, J.C. Wu, M.T. Longaker. Tissue Eng. Part A 19 (2013) 738-747.

125. Y. M. Kim, S.H. Oh, J.S. Choi, S. Lee, J.C. Ra, J.H. Lee, J.Y. Lim. Laryngoscope 124 (2014) E64-72.

126. H. Kim, K. Choi, O.K. Kweon, W.H. Kim, J. Dermatol. Sci. 68 (2012) 149-156.

127. J. Gu, N. Liu, X. Yang, Z. Feng, F. Qi. Biomed. Mater. 9 (2014) 035012.

128. S. Gomathysankar, A.S. Halim, N.S. Yaacob. Arch. Plast. Surg. 41 (2014) 452-457.

129. S.H. Hsu, P.S. Hsieh. Wound Repair Regen 23 (2015) 57-64.

130. Z. Lu, S.I. Roohani-Esfahani, G. Wang, H. Zreiqat. Nanomedicine 8 (2012) 507-515.

131. K. Choi, B.J. Kang, H. Kim, S. Lee, S. Bae, O.K. Kweon, W.H.Kim. J. Biomed. Mater. Res. B Appl. Biomater. 101 (2013) 919-928.

132. H.A. Declercq, T. Desmet, P. Dubruel, M.J. Cornelissen. Tissue Eng. Part A 20 (2014) 434-444.

133. W. Wan, S. Zhang, L. Ge, Q. Li, X. Fang, Q. Yuan, W. Zhong, J. Ouyang, M. Xing. Int. J. Nanomedicine 10 (2015) 1273-1290.

134. S. Liu, H. Zhang, X. Zhang, X.J. Zhang, W. Lu, X.H. Huang, H. Xie, J. Zhou, W.H. Wang, Y.J. Zhang, Y. Liu, Z.H. Deng, Y. Jin. Tissue Eng. Part A 17 (2011) 725-739.

135. M.A. Meruane, M. Rojas, K. Marcelain. Plast. Reconstr. Surg. 130 (2012) 53-63.

136. T.S. Iyyanki, L.W. Dunne, Q. Zhang, J. Hubenak, K.C. Turza, C.E. Butler, Tissue Eng. Part A 21 (2015) 475-485.

137. I. Komatsu, J. Yang, Y. Zhang, L.S. Levin, D. Erdmann, B. Klitzman, S.T. Hollenbeck. J Biomed. Mater. Res. A 101 (2013) 2939-2947.

138. M.W. Laschke, T.E. Schank, C. Scheuer, S. Kleer, S. Schuler, W. Metzger, D. Eglin, M. Alini, M.D. Menger. Acta Biomater. 9 (2013) 6876-6884.

139. K. Wang, L.Y. Yu, L.Y. Jiang, H.B. Wang, C.Y. Wang, Y. Luo. Acta Biomater. 15 (2015) 65-76.

140. G. Lin, M. Albersen, A.M. Harraz, T.M. Fandel, M. Garcia, M.H. McGrath, B.R. Konety, T.F. Lue, C.S. Lin. Urology 77 (2011) 1509 e1501-e1508.

141. Y.Y. Hsueh, Y.L. Chiang, C.C. Wu, S.C. Lin. Cells Tissues Organs 196 (2012) 117-128.

142. S. Gao, P. Zhao, C. Lin, Y.X. Sun, Y.L. Wang, Z.C. Zhou, D.J. Yang, X.L. Wang, H.Z. Xu, F. Zhou, L.M. Cao, W. Zhou, K. Ning, X. Chen, J. Xu. Tissue Eng. Part A 20 (2014) 1271-1284.

143. C.C. Shen, Y.C. Yang, B.S. Liu. J. Biomed. Mater. Res. A 100 (2012) 48-63.

144. L. Ma, Y. Yang, S.C. Sikka, P.J. Kadowitz, L.J. Ignarro, A.B. Abdel-Mageed, W.J.G. Hellstrom. Proc. Natl. Acad. Sci. U S A 109 (2012) 2090-2095.

145. X.B. Jin, Y.S. Sun, K. Zhang, J. Wang, T.P. Shi, X.D. Ju, S.Q. Lou. J. Biomed. Mater. Res. $A 86$ (2008) 1077-1087.

146. A. Kraus, C. Woon, S. Raghavan, K. Megerle, H. Pham, J. Chang. Plast. Reconstr. Surg. 132 (2013) 754e-766e. 
147. T. Martinello, I. Bronzini, A. Volpin, V. Vindigni, L. Maccatrozzo, G. Caporale, F. Bassetto, M. Patruno. J Tissue Eng Regen Med 8 (2014) 612-619.

148. M.J. Hung, M.C. Wen, Y.T. Huang, G.D. Chen, M.M. Chou, V.C. Yang. J. Formos. Med. Asso. 113 (2014) 704-715.

149. H.K. Cheung, T.T. Han, D.M. Marecak, J.F. Watkins, B.G. Amsden, L.E. Flynn. Biomaterials 35 (2014) 1914-1923.

150. B. Galateanu, D. Dimonie, E. Vasile, S. Nae, A. Cimpean, M. Costache. BMC Biotechnol. 12 (2012) 35.

151. B.H. Liu, H.Y. Yeh, Y.C. Lin, M.H. Wang, D.C. Chen, B.H. Lee, S.H. Hsu. Biores. Open Access 2 (2013) 28-39.

152. C. Ye, P. Hu, M.X. Ma, Y. Xiang, R.G. Liu, X.W. Shang. Biomaterials 30 (2009) 4401-4406.

153. A.D. Hanson, M.E. Wall, B. Pourdeyhimi, E.G. Loboa. J. Biomater. Sci. Polym. Ed. 18 (2007) 1387-1400.

154. P. Lund, L. Pilgaard, M. Duroux, T. Fink, V. Zachar. Cytotherapy 11 (2009) 189-197. 